\title{
Obituary: Professor Tom Schanz
}

It is with great regret that the Environmental Geotechnics panel have to record the death of Professor Tom Schanz, Head of Department on Foundation Engineering, Soil and Rock Mechanics at Ruhr University (Bochum, Germany), who passed away unexpectedly on 12 October 2017 on his way back home.

Professor Tom Schanz was born on the 24 May 1962 in Darmstadt, Germany. He studied Civil Engineering and Geology at the University of Stuttgart, Germany (October 1982-October 1988), graduating with a diploma in Civil Engineering. He graduated as Dr. Sc. Tech. from ETH Zurich in May 1994 and had a habilitation and venia legendi for geotechnics at University of Stuttgart in June 1998. He lived closed to Bochum with his wife, three children and his garden of roses of several species.

He was the professional co-worker in a public water supply company (March 1987-November 1987), a research assistant to Professor Dr.-Ing. P. Gussmann, IGS, at the University of Stuttgart (November 1988-May 1989) and to Professor H. J. Lang, IGT, at ETH Zurich, Switzerland (June 1989October 1993). He received a scholarship from the Kagoshima University, Japan, with the help of Professor Dr. R. Kitamura (May 1991-November 1991). He was working as senior engineer with Professor Dr.-Ing. U. Smoltczyk, IGS, University of Stuttgart (October 1993-April 1994), as a senior engineer/lecturer with Professor Dr.-Ing. P. A. Vermeer, IGS, University of Stuttgart (April 1994-September 1998). He had research contacts in nearly every university in Germany, in Eastern and Western Europe, and in countries overseas including Australia, Canada, Iraq, Japan and several other places in all over the world.

He was appointed as University Professor at the BAUHAUS-University Weimar, Germany, between October 1998 and April 2009, and at Ruhr University from April 2009 until now.

Professor Tom Schanz was involved in several technical committees of the International Society of Soil Mechanics and Geotechnical Engineering (ISSMGE TCS 105, 106, 208 and 308). He was a member of the Editorial Board of Environmental Geotechnics, Geotechnical Testing and the International Journal of Civil Engineering.

The doctoral thesis of Tom Schanz was on the investigations of the mechanical behavior of granular mixtures using the example of concrete recycling material (ETH Zurich in 1996). His habilitation was on modelling the mechanical behavior of frictional materials (University of Stuttgart in 1998). This was accompanied by two papers in Geotechnique with Professor Vermeer, his main theme tutor.

Tom Schanz was the youngest professor to hold the habilitation degree in Germany. He also supported the traditional topics of his professors, such as the kinematic element method. He created a scientific center after habilitation from post-doctoral and PhD students, at first in Weimar then in Bochum, with increasing laboratory and staff. His research assistants and post-doctoral and PhD students were selected from various parts of the world and his university became the meeting point in terms of scientific research from east to west.

Out of the post-doctoral students attracted to study under his tutorship, some are now working in Aachen (Germany), Göttingen (Germany), Cardiff (UK) and in several other universities around the world. He had $23 \mathrm{PhD}$

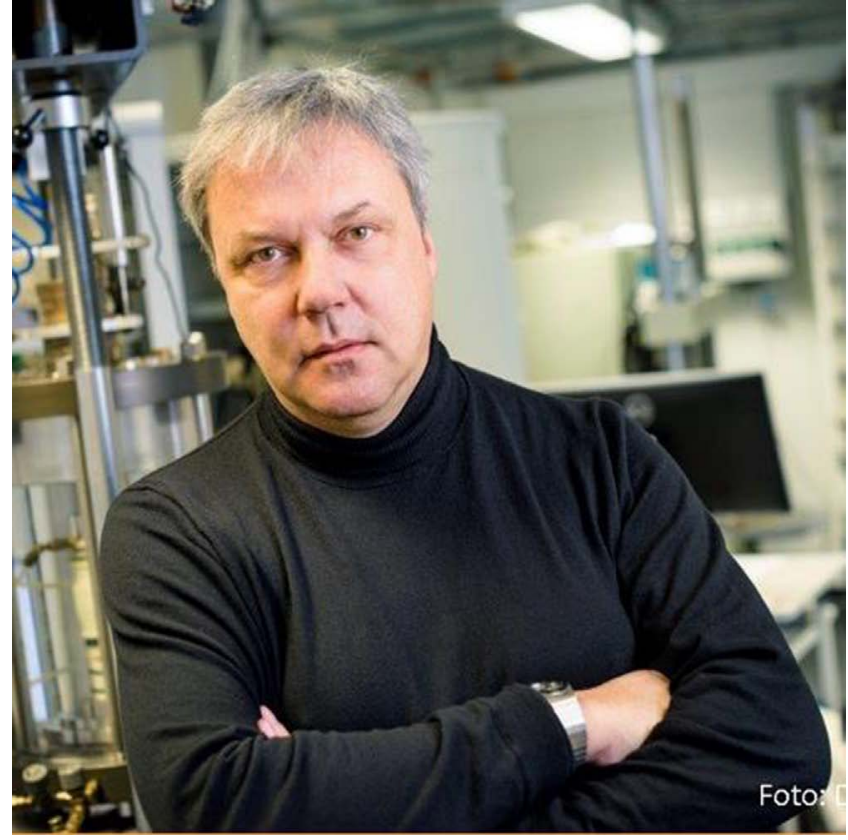

Professor Tom Schanz, 1962-2017

students who finished their thesis studies and several PhD students are presently working with a scholarship to work in a well-equipped research laboratory system at Bochum University.

His topics of research have been related to constitutive modelling and soil parameters, to theoretical and practical aspects of unsaturated soils mechanics (e.g. swelling clays, swelling pressure, suction, soil functions, bentonite contained mixtures), liquefaction problems (e.g. the effect of fines content), consolidation theories under constant and repetitive loading, inverse problems in theoretical and practical cases (from new inverse solvers to calibration modelling with Plaxis), engineering geology (e.g. special soils, landslides, characterisation of large areas), modern interdisciplinary topics (e.g. at boundary of geology, soil mechanics and energy science) and tunneling.

He published about 300 journal papers and organised numerous conferences. Several journal papers, as well as journal special issues have been planned and are under preparation. These journal issues will be completed in accordance with his suggestions.

He organised several symposia and conferences, the material of which has been published by Springer Proceedings in Physics since 2004. He invited numerous professors to give lectures to enhance technology transfer. He will be remembered around the world for his deep knowledge and warm hospitality. His seminars were always open for all interested people.

All who have been contact with him are grateful to him for his attention, support, help in all situation, and for the opportunity to learn. 